Svetlana M. Malkhazova ${ }^{1}$, Yang Linsheng ${ }^{3}$, Wang Wuyi ${ }^{3}$, Dmitry S. Orlov ${ }^{1 *}$,
Natalia V. Shartova

${ }^{1}$ Department of Biogeography, Faculty of Geography, Lomonosov Moscow State University, GSP-1, Leninskie Gory, Moscow, 119991, Russian Federation,

Tel: +7 (495) 9394717

2Department of Landscape Geochemistry and Soil Geography, Faculty of

Geography, Lomonosov Moscow State University, GSP-1, Leninskie Gory, Moscow, 119991, Russian Federation, Tel: +7 (495) 9392123

3 Institute of Geographical Sciences and Natural Resources Research (IGSNRR), Chinese Academy of Science (CAS), 11A, Datun Road, Chaoyang District, Beijing, 100101, China, Tel: +86-10-6488-9276

* Corresponding author, e-mail: orlovds@list.ru

\title{
HEALTH OF URBAN POPULATION IN MOSCOW AND BEIJING AGGLOMERATIONS
}

\begin{abstract}
The paper presents the results obtained under the joint Russian-Chinese RFBR project № 12-05-91175-ГФЕН_a aimed at assessment of the state of the environment and health of the population in urban areas in Russia and China. The paper presents the authors' approach to a comprehensive evaluation of the impact of the environment on the population health of urban agglomerations and a method of regional medico-geographical analysis. A series of analytical and synthetic maps was compiled and used for a comparative geographical analysis of medical and environmental situation in Moscow and Beijing - major metropolitan areas with different natural and socio-economic conditions. The paper discusses the influence of the environment on the state of public health and identifies the leading risk factors, both general and specific to each region.
\end{abstract}

KEYWORDS: urban agglomeration, Moscow, Beijing, public health, medico-geographical analysis

\section{INTRODUCTION}

Problems of the influence of the urban environment on public health has been a subject of interest for researchers since the early 1960s, when it became clear that a rapid change in the environment associated with the growth of cities and various social aspects have a very strong influence on human life [Environment ..., 1979]. Urban ecosystems have a number of unique features. In large cities, climatic, geophysical, and land conditions are transformed and gravity, magnetic, thermal, and electric fields of the Earth are modified. The environmental quality of cities affects life expectancy and health of the population, their physical and social activity, and demographic behavior [Malkhazova, Koroleva, 2011].

Benefits of urban forms of settlement are of mainly economic and social nature. Cities have developed production and social structure, health systems, communications, provide a high level of comfort, form a certain level of material and cultural values, and provide more opportunities for education and career choices. Large cities and capitals concentrate highly qualified specialists, including medical personnel and scientific and creative intelligentsia. Being the centers of gravity of human and material resources, cities create the most favorable conditions for life.

At the same time, the process of urbanization is associated with significant adverse environmental changes. Even remote regions are under the growing impact of urban areas. Risk factors for 
health in the urban environment involve its various components; the main negative consequence of human-induced changes is the environmental pollution [Rushton, Elliott, 2003; Wang, Krafft, 2008; Revich, 2010; Medical and Demographic ... 2011; Boas et al., 2011; Identification ..., 2014 et al.].

This paper discusses the results obtained under the joint Russian-Chinese RFBR project № 12-05-91175-ГФЕН_a aimed at assessment of the state of the environment and health of the population in urban areas in Russia and China. The authors present their approach to the integrated assessment of environmental impacts on health of urban agglomerations and a method of regional medico-geographical analysis. A series of analytical and synthetic maps was compiled and used for comparative geographical analysis of medical and environmental situation in Moscow and Beijing - major metropolitan areas with different natural and socio-economic conditions. The authors have analyzed the influence of the environment on the level of public health and have identified the leading risk factors, both general and specific to each region.

\section{MATERIALS AND METHODS}

The present-day medico-geographical studies are based on mathematical and statistical methods and techniques of mathematical and cartographic modeling. The authors have analyzed the existing methods and approaches to medical and environmental site assessments and have developed a method of assessment of the health status of the urban population. The approach was tested in Moscow and in Russia as a whole [Malhazova et al. 2010, 2012; Malhazova, Shartova 2013].

This procedure consists of several research stages involving both assessment of health indicators and the environmental factors that directly or indirectly affect health and livelihoods of the population.

The first phase consists of preparatory work; specifically, the main factors that affect health and livelihoods of the population of selected regions are selected. The information used in the analysis is based on the parameters that most clearly identify the impact of the urban environment on the population health. The information is selected based on expert assessment and analysis of literature, including details of environmental epidemiological, sanitary, and other studies, government reports on the state of the environment, and regulations [Environmental health indicators ..., 2002; Recommendations WHO ..., 2005]. Determination of the analyzed demographic and health indicators is based on the 10th WHO revision of the modern international classification of diseases (ICD-10) [International statistical classification of ..., 2003], used for recording and reporting the incidence, causes of death, and medical aid appealability of the population in the outpatient and inpatient health care system worldwide. The main components of the population in the analysis are children under the age of 14, men and women separately, and the overall population. Research can be conducted in dynamic (data analysis for a period of at least three years) or static aspects (a one-year "snapshot"). Special attention is given to social factors (unemployment, average wages, availability of health facilities, etc.) and anthropogenic load (condition of air, water, and soil) in analysis of the urban environment.

The second phase includes collection of statistical data on administrative units of the relevant health authorities and organizations that monitor the environment and of the Federal Service of State Statistics. Statistical data are collected for entire regions, for individual administrative units within the regions, and, if possible, for the administrative units within the analyzed cities. The information obtained is compiled into a thematic database of medical and environmental data. The database structure includes the following thematic blocks: demographic, morbidity of the population by class of diseases, incidence of socially relevant and environmentally-dependent diseases, environmental health, socio-economic indicators, and indicators of the health system.

These data are further compiled into a spatial database, i.e., (GIS), for the visualization of the 
research results and creation of cartographic products. The database structure allows timely updates with new data for various administrative and territorial levels.

Atthethirdphase,amathematical-cartographic modeling of health and environmental situation of territories is conducted. All the data are subjected to pre-analysis evaluation and ranked based on the identification of the maximum and minimum values and of their scatter. Medico-demographic and environmental factors are mapped based on this ranking. A series of analytical maps and a complement series of graphs reflect the spatial and temporal distribution of various medico-demographic, socio-economic, and environmental characteristics and are used for further analysis of the current state of the environment and public health.

Mathematical-cartographic modeling with methods of cluster analysis (dendrogram technique and K-means) are used for more in-depth study of the urban environment impact factors on the health of the population. It allows identification of groups of administrative units that are similar in terms of various nozoforms morbidity. A 10-score assessment method is used for the final integrated assessment of the environmental health situation.

The results of this comprehensive assessment of the health status are rendered cartographically. The main methods are cartograms and diagrammatic representation, traditionally used for mapping of phenomena for which data are presented in the context of the administrative-territorial units. Ranking is based on the natural gradation interval method with manual adjustment of the number of classes and their boundaries.

Comparative analysis of the health and vital activity of the population of different areas is doneat the final, fourth, phase of the medical and environmental analysis. This approach is called comparative-geographical method and is a traditional technique of medico-geographical research. Comparative geographical method is crucial in evaluations of different geographical processes and phenomena in relation to the state of health of the population in different regions. Many environmental factors and health indicators are measured and ranked in a clear quantitative form, which allows for a relative geographical comparison of these indicators and identification of regional specifics of study areas.

This approach utilized basic software applications: MS Excel, a specialized package for statistical data processing Statistica, a cartographic geoinformation system ArcGIS, and graphic editing tool Adobe Illustrator.

The algorithm's schematic representation is shown in Fig. 1.

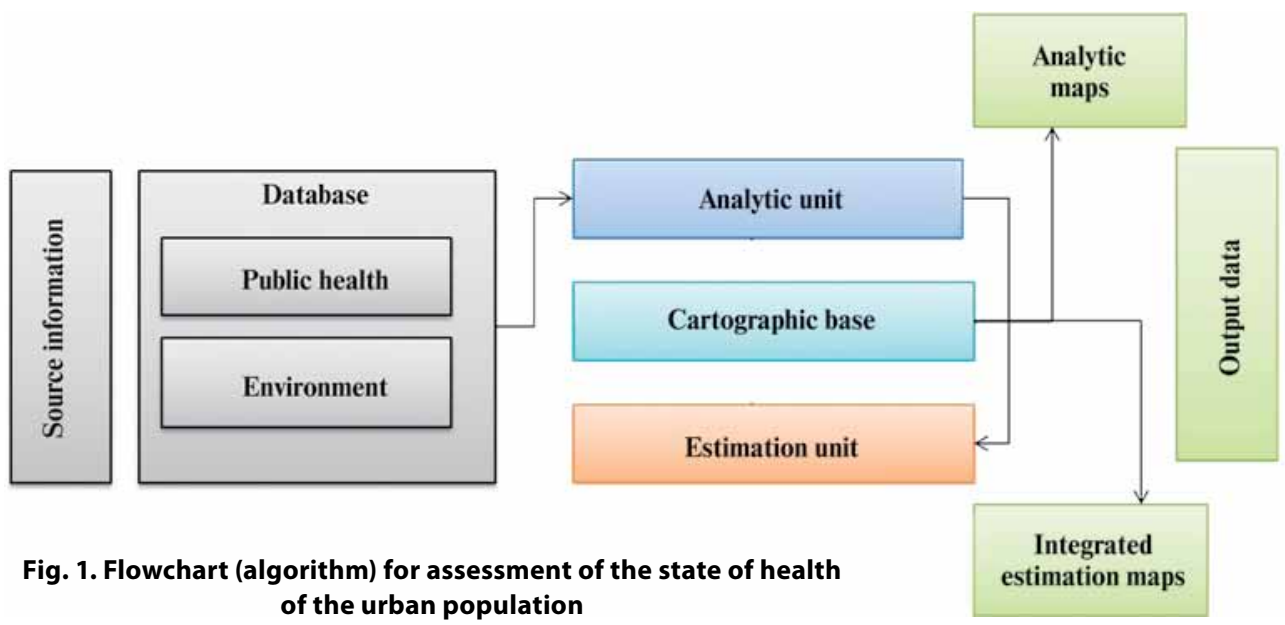


Depending on the purpose of research, this technique can be used for:

- preliminary assessment of the environmental health situation;

- obtaining information about specific environmental and geographical components of the urban environment and public health;

- integrated assessment of urban health and environmental factors influencing its condition.

\section{RESULTS AND DISCUSSION}

The created databases were used for a comparative analysis of environmental factors affecting the health status and medico-geographical situation for the two metropolitan regions - Beijing (the Beijing area included rural areas) and the Moscow region (Moscow city itself and the Moscow region), in 2000-2012. The data presented below correspond to the official statistics of 2009-2010 and, partially, to 2011-2012.

The territory of the Beijing region is 16 $808 \mathrm{~km}^{2}$ (the urban area is $1289 \mathrm{~km}^{2}$ ); the territory of the Moscow region - is 44379 $\mathrm{km}^{2}$ (the urban area is $2511 \mathrm{~km}^{2}$ ). The Beijing region is composed of a plain terrain (40\%) and mountainous areas (60\%) (elevation of up to $2303 \mathrm{~m}$.). The Moscow region is situated entirely on the East European Plain, with altitude difference of not more than $150 \mathrm{~m}$.

The population of Beijing is about 21 million people; population density is 1289 pop. $/ \mathrm{km}^{2}$. The population of the Moscow urban area is 12.1 million; population density is 4823 pop. $/ \mathrm{km}^{2}$. Population size and density of the Moscow region is much smaller, i.e., 7.1 million people and 160 pop. $/ \mathrm{km}^{2}$, respectively.

Analysis of the environmental components that may have a potential impact on the health status of the two urban regions, i.e., Moscow and Beijing, allows reaching the following conclusions.

Significant natural factors influencing the health status of the Beijing metropolitan area are associated with climatic conditions. The region has hot summers and cold winters (November to March). In spring (April and May), there are often strong winds causing sand and dust storms. Extreme weather conditions are also present. Thus, in the summer of 2010 , daily temperatures were $+38{ }^{\circ} \mathrm{C}-+42{ }^{\circ} \mathrm{C}$ for 22 consecutive days. The average annual rainfall is $585 \mathrm{~mm}$, including over $700 \mathrm{~mm}$ in the northern

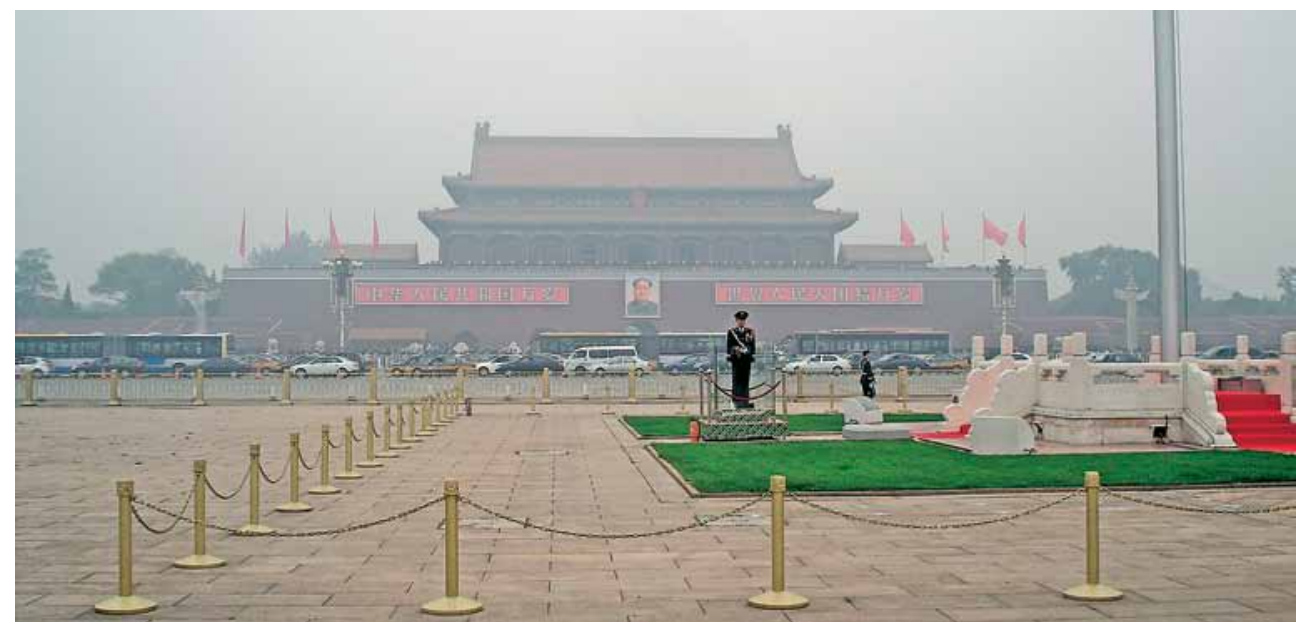

Fig. 2. Smog in Beijing (photo by D. Orlov) 
and western foothills and $450-600 \mathrm{~mm}$ in the southern part of the plains. About $85 \%$ of the precipitation falls during the wet season from June to September. In addition, there is a high degree of rainfall interannual variability. The minimum $(272 \mathrm{~mm}$ ) was recorded in 1869 and the maximum (1406 mm) - in 1959. These weather conditions favor the concentration of pollutants in the atmosphere and the formation of smog in the territory of Beijing (Fig. 2).

The climate of the Moscow region is moderately continental with distinct transitional seasons; it forms a very favorable environment for human health and vital activities. Currently, however, climatic changes associated with global processes are being observed. Thus, over the past decade, the average annual air temperature rose $1.5{ }^{\circ} \mathrm{C}$ compared to the multi-annual average temperature (in January, it increased by $4{ }^{\circ} \mathrm{C}$ and by $1-1.5^{\circ} \mathrm{C}$ in July); besides, there has been observed increased frequency of extreme climatic events. However, in general, we can note a less pronounced effect of climatic factors on the formation of the medico- geographical situation in the Moscow region, compared with Beijing.

Another important factor for the formation of a medico- geographical situation is the shortage of water availability in Beijing. The average volume of water is 3.77 billion $\mathrm{m}^{3}$, of which the surface water is 2.04 billion $\mathrm{m}^{3}$ and groundwater is 1.73 billion $\mathrm{m}^{3}$. Water availability per capita is less than $300 \mathrm{~m}^{3}$ per year, which is significantly less than the international standard of water supply (1000 $\mathrm{m}^{3}$ per capita per year) for the country.

In total, there are 85 water reservoirs in Beijing with a total volume of 9.35 billion $\mathrm{m}^{3}$, and 50000 groundwater wells. The capacity of water supply is 0.6 million $\mathrm{m}^{3}$ per day. About $90 \%$ of wastewater is treated directly in the city center. In general, this region has the excessive use of both surface water and groundwater. Much of the time, most of the rivers are dry; conditions of river ecosystems are deteriorating. There is a high degree of water pollution: about $50 \%$ of river water belongs to the class 3 quality. At the same time, there is a low level of treated wastewater (76\% in 2009).

In the Moscow region, there are more than 900 rivers and 1000 streams, a large number of lakes, and 13 main-maid reservoirs. The total volume of the reservoirs with volumes of more than 10 million $\mathrm{m}^{3}$ is 1270 million $\mathrm{m}^{3}$. It should be emphasized that, for the Moscow region, the water availability factor is not a problem factor in respect to public health.

The priority socio-economic factor that has the greatest impact on the health status of the population in both regions is the intensive economic development and, as a consequence, the increasing urbanization accompanied by the growing anthropogenic load. Both regions have a long history of exploration and development; however, in the Moscow region, compared with Beijing, the transformations of recent years are less intense. Currently, 27 new free economic zones are reported in Beijing; there are more than 10000 construction sites with the total area of 100 million $\mathrm{m}^{2}$ annually. A characteristic feature of the transformation in Beijing is rapid change of the old city center.

Despite significant economic development of Beijing, continuous use of coal as fuel remains an important factor for the region affecting the health of the population. One of the areas of improvement of the medical and environmental situation in Beijing is the prevention and mitigation of particulate pollution, transformation of the energy system, and the transition to natural gas consumption.

The inevitable consequence of strong economic development of the regions is the high traffic load. A significant increase of the number of vehicles in recent years has caused air pollution. Thus, in 2010, in Beijing, there were 4.5 million cars (including 2 million privately owned). According to 
estimates, the number of cars is increasing daily by more than 1900 . According to official data in 2011, the number of registered cars in Moscow was 4.1 million. Over the last two years, the number of registered motor vehicles more than doubled.

The main measures to prevent the further deterioration of the air quality include new licensing of trucks and motorcycles, standardization of fuel for local vehicles, and control of exhaust pollutants from vehicles. These activities are being currently implemented with varying degrees of intensity in both regions.

Another possible solution to this problem is the development of alternative modes of transportation, such as subways and electrical trains. According to the development plan of the Beijing metropolitan area, 16 new subway lines (stations), 6 light-rail lines, and 6 lines of suburban electrical trains will be built by 2020. Moscow plans to build more than $160 \mathrm{~km}$ of new lines and open 78 metro stations from 2011 to 2020.

Thus, the common factors influencing the health state of the population of the Beijing and Moscow regions include the strong anthropogenic transformation of the territory, significant traffic load, and poor state of the atmosphere.

Specific factors in Beijing include shortage of water resources and poor quality of drinking water, fuel and energy system that uses coal as fuel, and extreme climatic conditions. In Moscow, these factors typically do not have a pronounced negative impact on the health state of the population.

Analysis of the medicodemographic situation in the considered regions has identified population growth as the important factor of impact in Beijing, where in the period from 1949 to 1990, the population has increased from 2 to 10 million, reaching 19.7 million in 2010. In addition, in 2010, 2.3 million migrants were recorded.

The growth of the population of Moscow is quantitatively less pronounced; however, the rate of increase is very similar. Thus, from 1969 to 2010, the population has increased from about 6 million to 11.9 million.

Life expectancy for the population of Beijing in 2010 was 80.5 years, with 78.6 years for men and 82.4 years for women. The population older than 60 years and older than 65 years is $13.1 \%$ and $8.4 \%$ of the total number of residents, respectively.
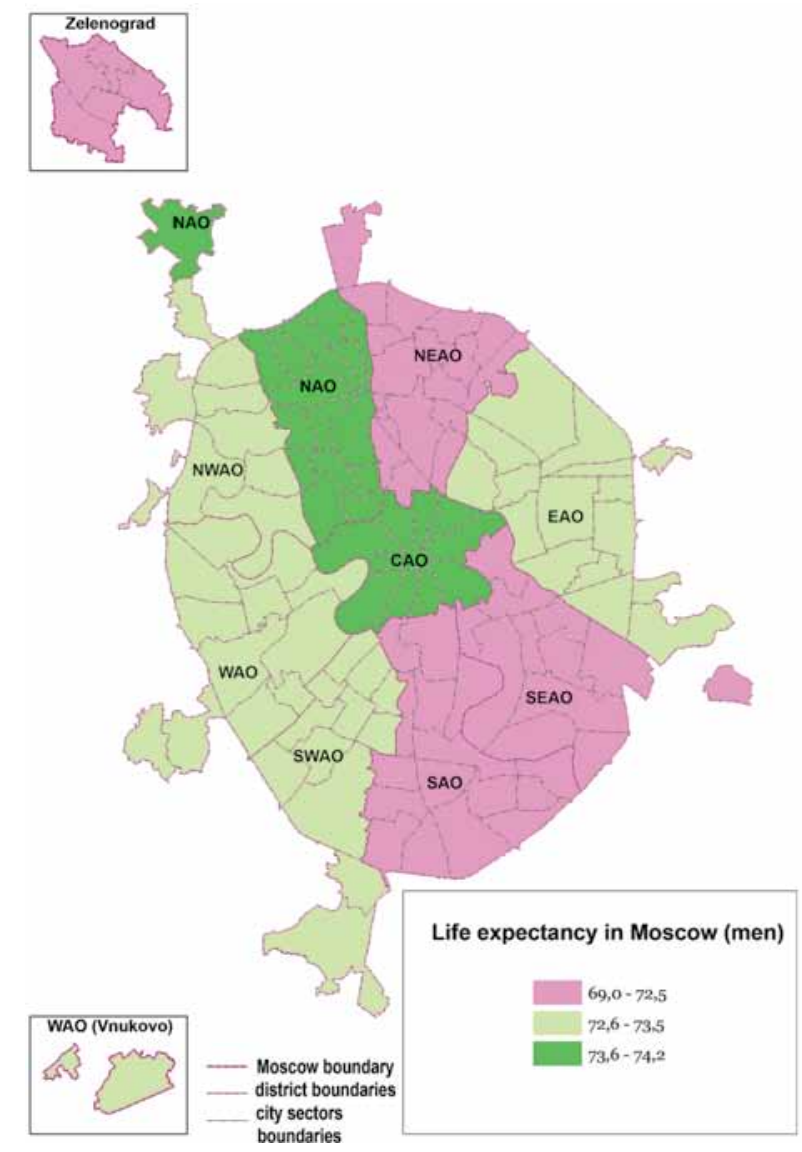

Fig. 3. Life expectancy) 
Life expectancy in Moscow is lower, i.e., 73.6 years, with 69.4 years for men and 77.7 years for women (Fig. 3 a-b).

The main causes of death in Beijing are cancer, cardiovascular diseases, respiratory diseases, injuries and poisoning, and diseases of the endocrine system. Mortality from cancer is $25.7 \%$ of total mortality and has the annual growth of $2.5 \%$ over the past 10 years. Prevailing malignancies include lung and breast cancer.

The main causes of death in Moscow are diseases of the circulatory system (55\%), malignant neoplasms (17\%), injury and poisoning (15\%), digestive diseases (6\%), and respiratory diseases (5\%).
Considering the state of health of the analyzed regions, it should be noted that in Beijing, there is a significant incidence of infectious diseases, including intestinal infections (typhoid, paratyphoid, bacillary dysentery, and infectious diarrhea) (Figs. 4 and 5).

The return of some particularly dangerous infectious diseases, such as the plague, is becoming relevant to the territory of China due to climate change [Wang et al, 2009].

The special problems include periodic emergence and spread of new infections in the region, such as SARS, swine flu, etc. Epidemics occur usually in cities with a significant concentration of people [Ngeow et al., 2005; Zhou et al., 2011; Yang et al., 2012].

In Moscow, there is prevalence of chronic diseases such as cardiovascular disease (648 per 100000 population), malignant neoplasms (209 per 100000 population), digestive diseases (44 per 100000 population), and respiratory diseases (28 per 100 000 population) (Fig. 6).

\section{CONCLUSION}

Analysis of the medicogeographical situation of the studied regions led to the following conclusions. Despite the fact that these regions have a number of similar environmental factors affecting the health status of the population (such as the strong anthropogenic transformation of the territory, significant traffic load, and poor state of the air quality), differences in natural conditions result in significant differences in the state of the population health. Lifestyle of the population, including in the historical past, obviously plays the important role. 


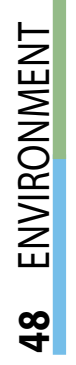

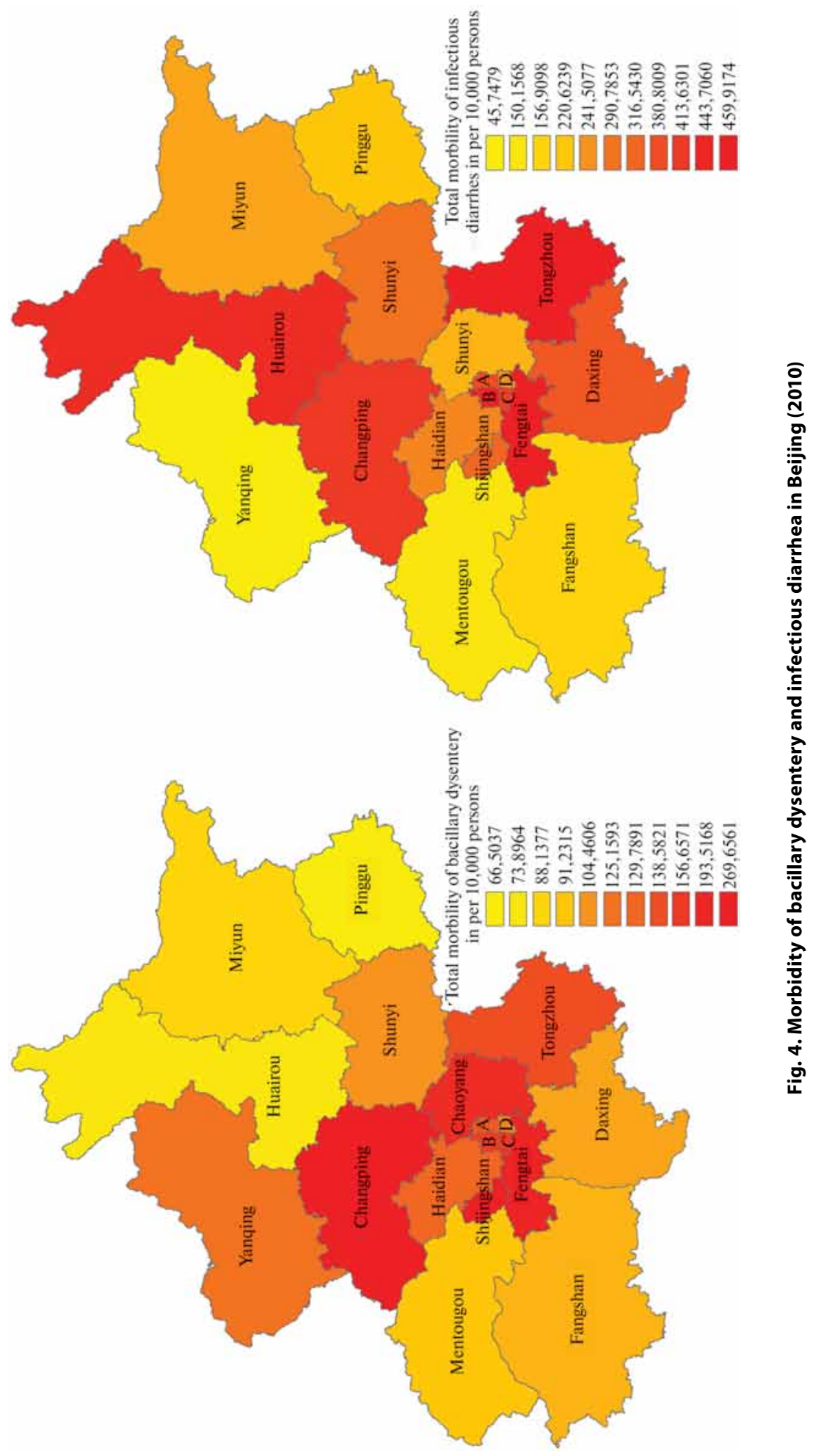




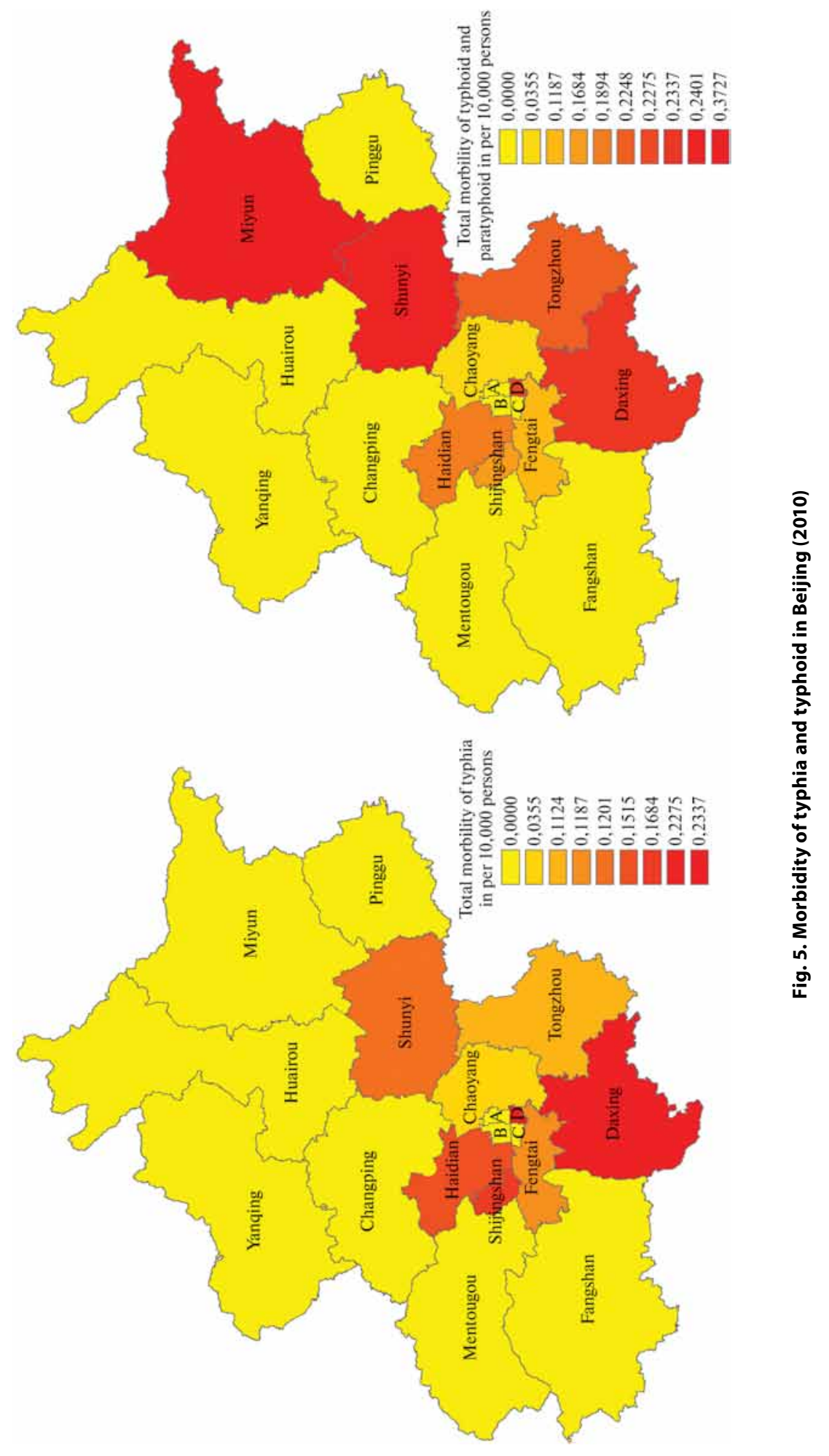



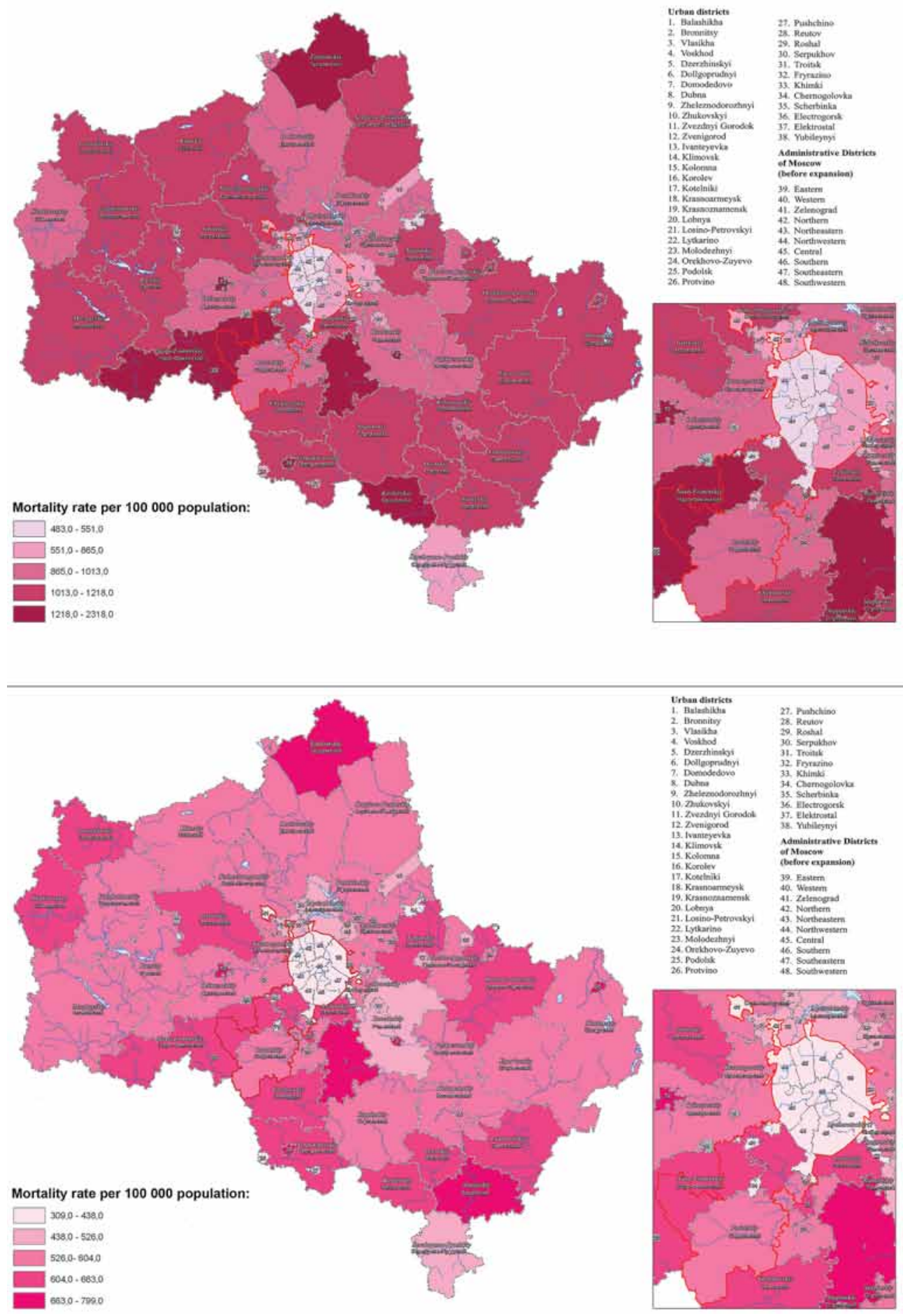

Fig. 6. Mortality from cardiovascular diseases in cities and districts of the Moscow region (2010):

$$
a \text {-men, } b \text {-women }
$$


Varying degree of intensity of socioeconomic changes is also reflected in the state of the population health. The rapid development of new areas of Beijing attracts a significant number of migrants and entails outbreaks of infectious diseases. The longterm development of the Moscow region, as a large industrial center, results in the high level of chronic non-communicable diseases.

Significant differences in the major causes of mortality and life expectancy can be associated with the organization of the health system in the regions and levels of its development.

\section{ACKNOWLEDGEMENTS}

This work was supported by the grant of the Russian Foundation for Basic Research (RFBR) № 12-05-91175-ГФЕH_a, Project of the Russian Geographical Society (№ 05 / 2013 P1 - non-repayable assistance, June 24, 2013) and Project № 41110117 of the National Natural Science Foundation of China (NFSC).

\section{REFERENCES}

1. Boas M., Feldt-Rasmussen U., Main K.M. (2011) Thyroid effects of endocrine disrupting chemicals // Molecular and Cellular Endocrinology. No. 355 (2). P. 240-248.

2. Environment and Health (1979). - M.: Nauka - 214 p.

3. Environmental Health Indicators for the WHO European Region, WHO (2002).

4. Identification of risks from exposure to endocrine-disrupting chemicals at the country level (2014) // World Health Organization. 32 p.

5. International statistical classification of diseases and related health problems. ICD-10. (2003). - M.: Medicine, Vol. 1. - 741 p.

6. Malkhazova, S.M., Koroleva, E.G. (2011) Environment and Human Health: A Training Manual. - M.: Geography Faculty of Moscow State University. - 180 p.

7. Malkhazova, S.M., Semenov, V.Yu, Shartova, N.V., Gurov, A.N. (2010) The population health of the Moscow region: Medico-geographical aspects. GEOS, Moscow - 112 p.

8. Malkhazova, S.M., Shartova, N.V. (2013) Spatial-temporal analysis of the mortality of the population of Moscow region // Geoenvironmental Problems of New Moscow. - MediaPress, Moscow. - pp. 38-43.

9. Malkhazova, S.M., Shartova, N.V., Krainov, V.N., Orlov, D.S. (2012) Spatial-temporal analysis of the mortality of the population for the purpose of environmental monitoring // Problems of Regional Ecology. № 4. pp. 154-160.

10. Medico-Demographic Forecasting: Study Guide (2011) Prokhorov, B.B., Ivanova, E.I., Shmakov, D.I., Shcherbakov, E.M. - M.: MAKS Press. - 360 p.

11. Ngeow Y., Suwanjutha S., Chantarojanasriri T., Wang F., Saniel M., Alejandria M., Hsueh P., Ping-Ing L., Park S., Sohn J., Aziah A., Liu Y., Seto W., Cecilia L., Ngan C., Hadiarto M., Hood A., Cheong Y. (2005) An Asian study on the prevalence of atypical respiratory pathogens in community-acquired pneumonia. Int. Journal of Infectious Diseases. Vol. 9. pp. 144-153.

12. Recommendations $\mathrm{WHO}$ on air quality guidelines for particulate matter, ozone, nitrogen dioxide, and sulfur dioxide, WHO (2005).

13. Revich, B.A. (2010) Environmental priorities and health: vulnerable areas and populations // Human Ecology. № 7. pp. 3-9. 
14. Rushton L., Elliott P. (2003) Evaluating evidence on environmental health risks // British Medical Bulletin. No. 68. P. 113-128.

15. Wang W.Y., Krafft T. (2008) Urbanization and health-Challenges for China. In M. Exner, G. Klein, A. Rechkemmer, \& F. Schmidt (Eds.), Source-Publication Serires of UNU-EHS: Towards Sustainable Global Health. Bonn, Germany. pp. 77-84.

16. Wang Z., Chen H., Zheng Y., Wu K. (2009) Types and Distribution of Plague Natural Foci in China. Beijing: Science Press; 264.

17. Yang H., Qiao C., Tang X., Chen Y., Xin X., Chen H. (2012) Human infection from avian-like influenza A (H1N1) viruses in pigs, China. Emerg Infect Dis 18. pp. 1144-1146.

18. Zhou H., Wang C., Yang Y., Guo X., Kang C., Chen H., Jin M. (2011) Pandemic (H1N1) 2009 virus in swine herds, People's Republic of China. Emerg Infect Dis 17. pp. 1757-1759.
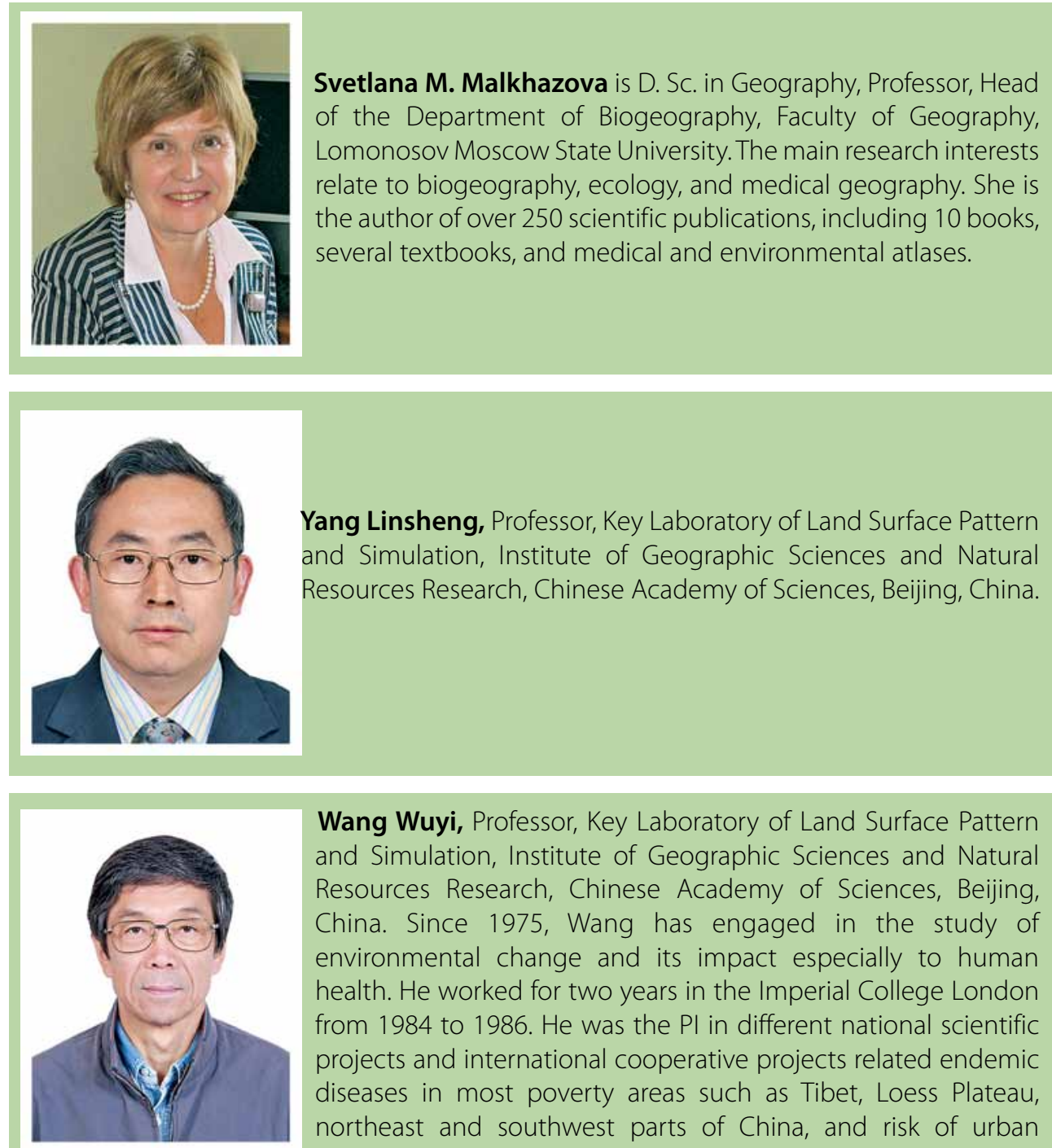

Wang Wuyi, Professor, Key Laboratory of Land Surface Pattern and Simulation, Institute of Geographic Sciences and Natural Resources Research, Chinese Academy of Sciences, Beijing, China. Since 1975, Wang has engaged in the study of environmental change and its impact especially to human health. He worked for two years in the Imperial College London from 1984 to 1986 . He was the PI in different national scientific projects and international cooperative projects related endemic diseases in most poverty areas such as Tibet, Loess Plateau, northeast and southwest parts of China, and risk of urban environmental health. He is the co-chair of the Commission on Health and the Environment of the International Geographical Union (IGU), chairman of the Committee of Medical Geography, the Geographical Society of China. 

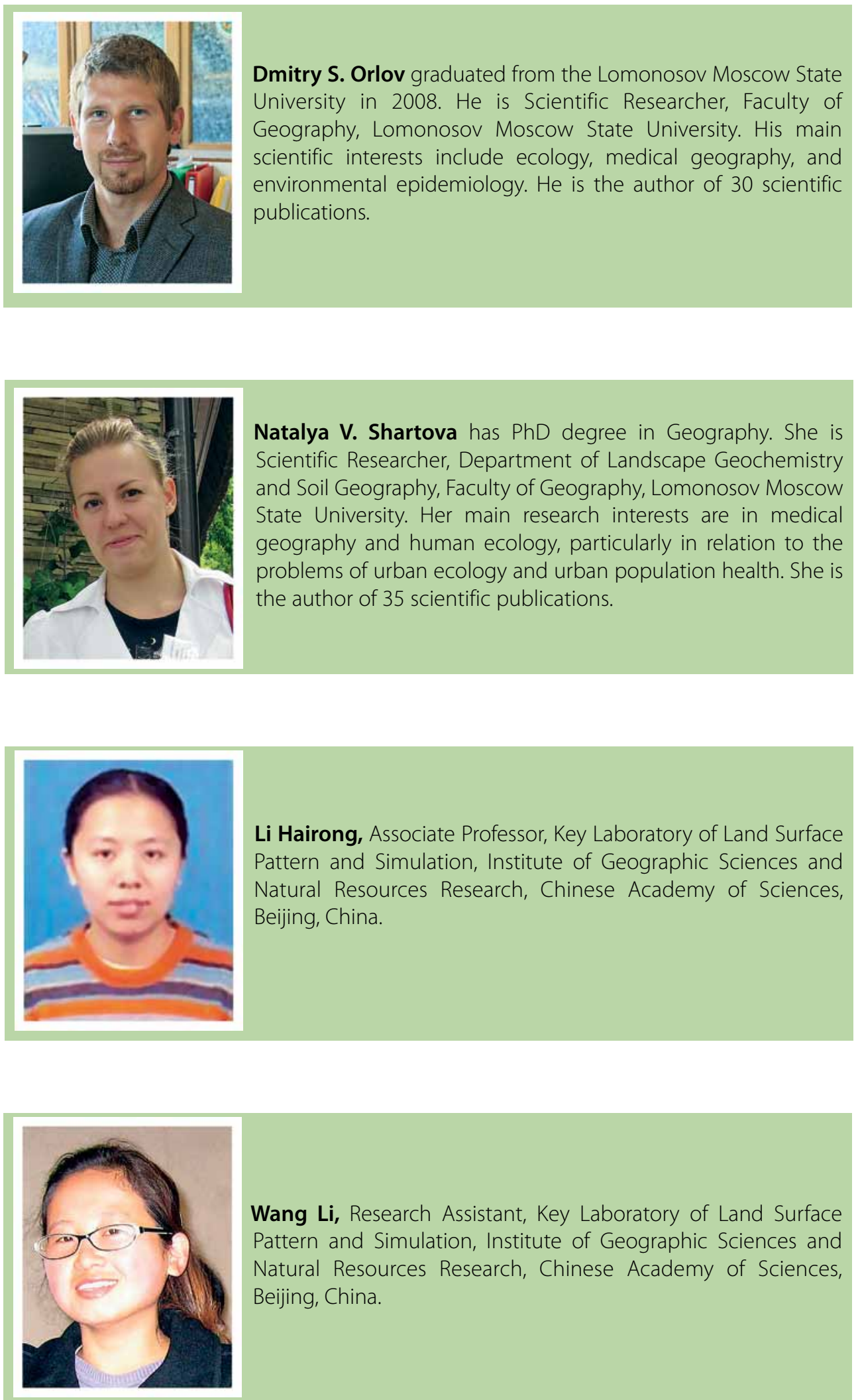

Wang Li, Research Assistant, Key Laboratory of Land Surface Pattern and Simulation, Institute of Geographic Sciences and Natural Resources Research, Chinese Academy of Sciences, Beijing, China. 